\title{
Hysterosalpingographic findings in infertility - what has changed over the years?
}

\author{
Olubukola AT Omidiji, ${ }^{1}$ Oluyemisi O Toyobo ${ }^{2}$, Omololu Adegbola, ${ }^{3}$ Abiodun Fatade, ${ }^{2}$ Omodele A Olowoyeye ${ }^{1}$
}

1. Department of Radiation Biology, Radiotherapy, Radiodiagnosis and Radiography, College of Medicine, University of Lagos/ Lagos University Teaching Hospital, Idi-Araba, Lagos.

2. Crestview Radiology, Lagos, Nigeria.

3. Department of Obstetrics and Gynaecology, College of Medicine, University of Lagos/Lagos University Teaching Hospital, Idi-Araba, Lagos.

$\begin{array}{lll}\text { Emails: } & & \\ \text { Omidiji O.A.T: } & \text { olubukolaomidiji@yahoo.com } & +2348122167403 \\ \text { Toyobo OO: } & \text { drtoyobo@yahoo.com } & +2348023114772 \\ \text { Adegbola O: } & \text { omololuadegbola@gmail.com } & +2348023225033 \\ \text { Fatade A: } & \text { ffatad@yahoo.com } & +2348055040083 \\ \text { Olowoyeye OA: } & \text { molowoyeye@gmail.com } & +2348084065046\end{array}$

\begin{abstract}
Background: Prior studies on Hysterosalpingography (HSG) have shown that pelvic inflammatory disease (PID) related tubal adhesions accounted for $30-50 \%$ of female infertility, with as high as $80 \%$ reported in some studies. With improved access to contraceptives, antibiotics and promotion of safe practices, the abnormal findings in HSG may have reduced or altered.

Objective: To document the imaging findings in the HSG of participants and to compare current findings with prior studies done nationally and internationally.

Method: A retrospective evaluation of 974 HSGs done at the tertiary diagnostic center over a 7-year period was conducted and analyzed using diagnostic accuracy tables.

Results: Tubal pathologies were the most common abnormality in this study, (35.1\% of the cases), comprising tubal blockage and hydrosalpinges; followed by uterine masses seen in $223(22.9 \%)$ of the clients. Tubal occlusion was higher in clients with multiple abnormal findings; .while normal sized and large uterine cavities had a higher percentage of bilateral tubal patency.

Conclusion: Tubal factors remain the most common abnormality seen in the HSGs of infertile women in this study, though with lower prevalence compared with prior older studies. Forty seven (47\%) of the cases of female factor infertility had normal HSGs with bilateral tubal patency.
\end{abstract}

Keywords: HSG, infertility, female, Africa, tubal factors, uterine masses.

DOI: https://dx.doi.org/10.4314/ahs.v19i2.9

Cite as: Omidiji OAT, Toyobo OO, Adegbola O, Fatade A, Olowoyeye OA. Hysterosalpingographic findings in infertility - what has changed over the years? Afri Health Sci.2019;19(2): 1866-1874. bttps:/ / dx.doi.org/10.4314/abs.v19i2.9

\section{Corresponding author:}

Olubukola AT Omidiji,

Department of Radiation Biology,

Radiotherapy, Radiodiagnosis

and Radiography, College of Medicine,

University of Lagos/ Lagos University

Teaching Hospital, Idi-Araba, Lagos

Tel: +2348122167403

Email Address: olubukolaomidiji@yahoo.com

\section{Introduction}

Hysterosalpingography (HSG) is a radiologic study done under fluoroscopy to visualize the uterine cavity and lumen of the fallopian tubes as part of assessment for female factor infertility. ${ }^{1}$ It involves contrast instillation via cannulation of the cervix ${ }^{1}$.

HSG has been in existence for over 100years. ${ }^{2}$ In 1914, Carey used collergol for the first HSG. ${ }^{2}$ Lipiodol was introduced by Sicard and Forestier in 1924 and remained a popular contrast medium for many decades. ${ }^{3}$ Water-solu- 
ble contrast material was later employed and was preferable as it avoided the possible complication of oil embolism. ${ }^{2}$ Despite its longevity, HSG is still one of the first line modalities in assessing for infertility, due to its low cost and less-invasiveness compared to laparoscopy. ${ }^{4}$

Modifications of the procedure have been made in the last 20 years, ${ }^{5}$ including selective hysterosalpingography (tubes are selected individually and contrast introduced), sonosalpingography (instillation of saline under ultrasound guidance) and ultrasound contrast enhanced hysterosalpingography (instillation of contrast medium, Hycosy, via ultrasound guidance). Other techniques also exist (laparoscopy and hysteroscopy) and have been deemed superior. ${ }^{4}$ They are however invasive and done in cases when the tubal affectation on HSG is unclear, normal with no conception after 6 months or where treatment is required. Magnetic resonance imaging is another useful modality, mainly for the uterus and ovaries.

Infertility is defined as the failure to achieve cyesis after 12 months or more of regular unprotected sexual intercourse. ${ }^{6}$ This can be primary or secondary; secondary infertility being inability to conceive after an earlier pregnancy. The prevalence of infertility in numerous studies in sub-Saharan Africa ranges from $20-46 \%{ }^{4}$ A study on the pattern and challenges of infertility in Lagos, Nigeria attributed $11.1 \%$ of infertility cases to solely male factors, $37.8 \%$ to female factors, $40 \%$ to both male and female factors and $11.1 \%$ to no identifiable factors. ${ }^{7}$ Identified etiological factors of infertility include sexually transmitted diseases, complications of unsafe abortions, and puerperal pelvic infections. ${ }^{4}$

The primary role of HSG is to assess the morphology and patency of the tubes. ${ }^{6}$ Prior studies on HSG have shown that pelvic inflammatory disease (PID) related tubal adhesions account for $30-50 \%$ of female infertility. ${ }^{1,4,6} \mathrm{~A}$ much higher rate of $81 \%$ was even reported in a study in South Africa ${ }^{8}$ and a much lower rate in India of $25-35 \% .{ }^{9}$ Other causes of female infertility seen on HSG include but are not limited to uterine abnormalities such as filling defects due to masses or mucosal irregularities and mullerian duct anomalies. ${ }^{6}$

The aim of this study is to assess the imaging findings of studies done at a Radiology diagnostic centre over a 7-year period (1 March 2010 to 28 Feb 2017), compare with other studies done nationally and internationally and assess changes, especially with readily available and af- fordable antibiotics, increased use of contraceptives, promotion of safe practices and condoms regarding sex and self medication in Nigeria. It is hoped that this will add to the available knowledge and aid in the management of infertility in our environment.

\section{Methods}

This was a cross-sectional study to determine the imaging findings in hysterosalping ograms of clients who presented at a tertiary diagnostic centre and assess changes in pattern of findings with studies done nationally and internationally. The diagnostic centre receives referrals from Lagos and its environs and provides radiological services with equipment such as digital X-ray, Fluoroscopy, 4D ultrasound and Digital Mammography, 10 with an average of 7 requests for HSG per week.

A retrospective evaluation of all HSGs performed at the centre over a 7-year period (1 March 2010 - 28 February 2017) was done and the findings documented. The sociodemography and pertinent gynaecologic history such as age, parity and duration of infertility of each subject were retrieved from the database. Individual consent was not necessary as it was a retrospective study with no patient contact. In line with the standard practice, subjects with vaginal discharge, bleeding and recent instrumentation were excluded from the procedure and referred for appropriate management

A fluoroscopy machine Apelem VBS, manufactured in 2007 was used for the procedure. At the centre, the procedure was explained to the patient and the patient was booked during the proliferative phase of the menstrual cycle between day 8 and 12 of the menstrual cycle, when the endometrium is thinnest. ${ }^{10-11}$ Patients were advised to abstain from sexual intercourse from the start of their period till after the procedure. At our centre, it is our practice to conduct pregnancy tests for clients prior to the procedure when clients have not complied with the advice or pregnancy is suspected. It is mandatorily done in clients being evaluated for amenorrhoea. A proforma detailing clinical and gynaecological history was administered to the patient. Consent was then obtained both verbally and in written form. The standard protocol for performing HSGs was followed. ${ }^{10}$

The HSG images were retrieved from the Picture Archiving and Communications System (PACS); and three 
experienced radiologists conducted morphologic evaluation of the retrieved images and their observations were documented. The uterine cavities were classified using their width as small $(<2.5 \mathrm{~cm})$, normal $(2.5-3.5 \mathrm{~cm})$ and large $(>3.5 \mathrm{~cm})^{12}$

The data was entered using Microsoft excel and analyzed using the SPSS for windows version 22 program. The frequency of the pathologies seen was calculated. Correlations between the pathology and presence of spillage were obtained using Chi square test. Mean values and distribution of variables were also presented.

Ethical approval was obtained from the Health Research and Ethics Committee, Lagos University Teaching Hospital, Idi-Araba.

\section{Results}

974 hysterosalpingograms (HSGs) done at the diagnostic facility over a 7-year period were reviewed.Majority of the clients were in the $30-34$ age group, 331 (34\%) and the least $2(0.2 \%)$ in the 45 and above age groups. Age range was $20-52$ years and their mean age was $33.9+5.4$ years. Uterine cavity characteristics are outlined in table 1 namely the size of the cavities, presence of masses and adhesions (figs 1\&2). The uterine cavities were normal in majority of the HSG; $771(79.2 \%)$ and not demonstrable in few of the cases $7(0.7 \%)$. Mass impressions were seen in $223(22.9 \%)$ of the cases while adhesions were noted in $143(14.7 \%)$.

With regards to tubal factors, hydrosalpinx was seen in 91 $(9.4 \%)$ which was bilateral in 36 (3.7\%). Unilateral hydrosalpinx was more common on the left in $33(3.4 \%)$, while unilateral spillage occurred more on the right 88 (9.0\%). Table 1, figure 3

Table 1: Frequency distribution of tubo-uterine abnormalities and correlation with spillage

\begin{tabular}{|c|c|c|c|}
\hline $\begin{array}{l}\text { Parameter } \\
N=974(100)\end{array}$ & $\begin{array}{l}\text { Spillage } \\
\text { Present }\end{array}$ & Spillage Absent & p \\
\hline \multicolumn{4}{|l|}{ Mass } \\
\hline $\begin{array}{l}\text { No mass } \\
N=751(77.1)\end{array}$ & $642(85)$ & $109(15)$ & \\
\hline $\begin{array}{l}\text { Mass present } \\
\mathrm{N}=223(22.9)\end{array}$ & $183(82)$ & $40(18)$ & $\mathrm{P}=0.12$ \\
\hline \multicolumn{4}{|l|}{ Hydrosalpinx } \\
\hline Left $33(3.4)$ & $23(69.7)$ & $10(30.3)$ & \\
\hline Right $22(2.2)$ & $15(68.2)$ & $7(31.8)$ & \\
\hline Both $36(3.7)$ & $20(55.6)$ & $16(44.4)$ & \\
\hline Nil $883(90.7)$ & $767(86.9)$ & $116(13.1)$ & $p=<0.01$ \\
\hline \multicolumn{4}{|l|}{ Uterus } \\
\hline Small $19(2.0)$ & $6(31.6)$ & $13(68.4)$ & \\
\hline Large $177(18.2)$ & 145 (81.9) & $32(18.1)$ & \\
\hline Normal 771 (79.2) & $674(81.7)$ & $97(12.6)$ & \\
\hline Absent $7(0.7)$ & $\theta(0)$ & $7(100)$ & $f<0.00$ \\
\hline \multicolumn{4}{|l|}{ Other findings } \\
\hline Ashermann $24(100)$ & $9(37.5)$ & $15(62.5)$ & \\
\hline Cervical stenosis $5(100)$ & $0(0)$ & $5(100)$ & \\
\hline Cervical adhesions 39 (100) & $8(11.5)$ & $31(79.5)$ & \\
\hline Septate uterus 1 (100) & 0 & $1(100)$ & \\
\hline Arcuate uterus 1 (100) & 0 & $1(100)$ & $f<0,00$ \\
\hline Pelvic adhesions 6 (100) & 0 & $6(100)$ & \\
\hline Tubal rings $1(100)$ & 0 & 1 & \\
\hline
\end{tabular}




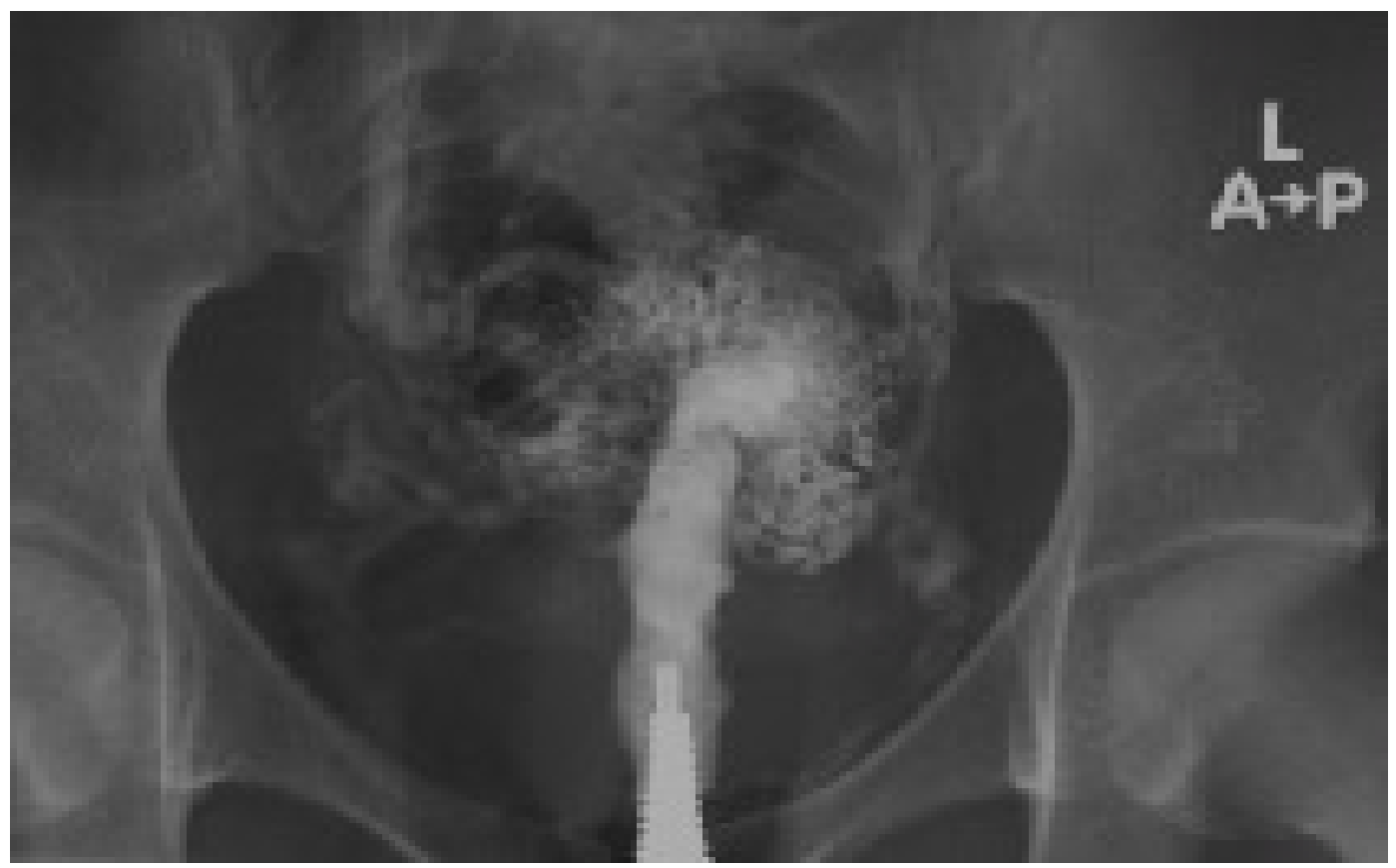

FIG 1: Hysterosalpingogram demonstrates a small and conical uterine cavity with extravasation on further contrast of contrast - Ashermann's

The proportion of dye spillage in those with uterine masses, hydrosalpinx and other abnormal findings are also outlined in table 1 . Statistically significant findings ( $p<0.01)$ were seen as follows: clients with normal and large uterine cavities had a higher percentage of spillage or tubal patency. (fig. 4). Clients with Asherman's disease, cervical stenosis and adhesions had less percentage of tubal spillage than those without.
Figure 5 shows the distribution of abnormal findings in the study. Tubal pathologies were the most common abnormality in this study, constituting $35.1 \%$ of the cases. The tubal abnormalities comprised of tubal blockage, absence and hydrosalpinges, followed by uterine masses seen in $223(22.9 \%)$ of the clients. Bilateral tubal blockage was seen in $106(10.6 \%)$. The least was uterine malformations such as septate and arcuate uterus in $1(0.1 \%)$ each.

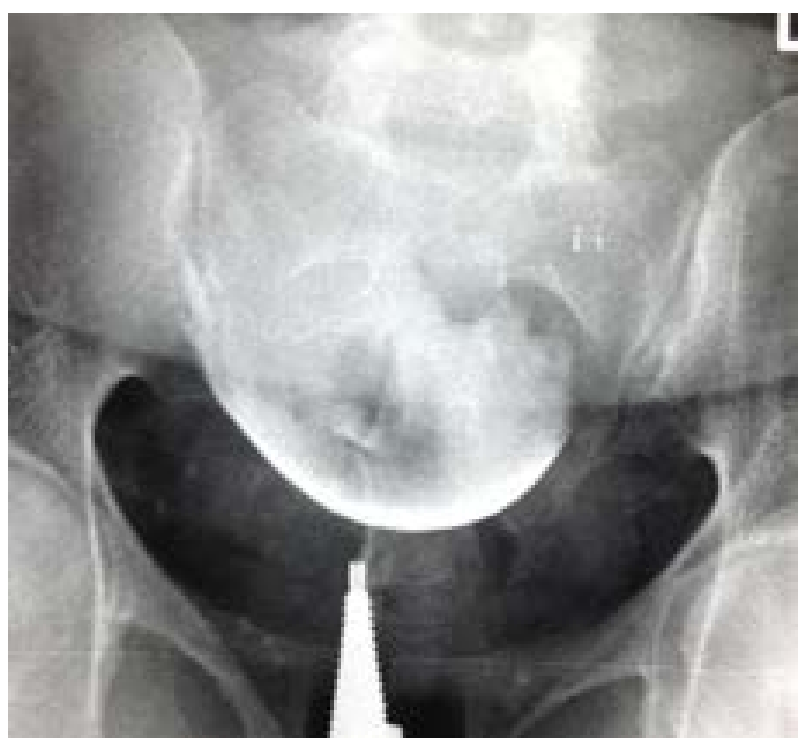

Fig 2: hysterogram showing a grossly enlarged uterine cavity with a large filling defect/mass - Submucosal myoma. The tubes are not outlined 


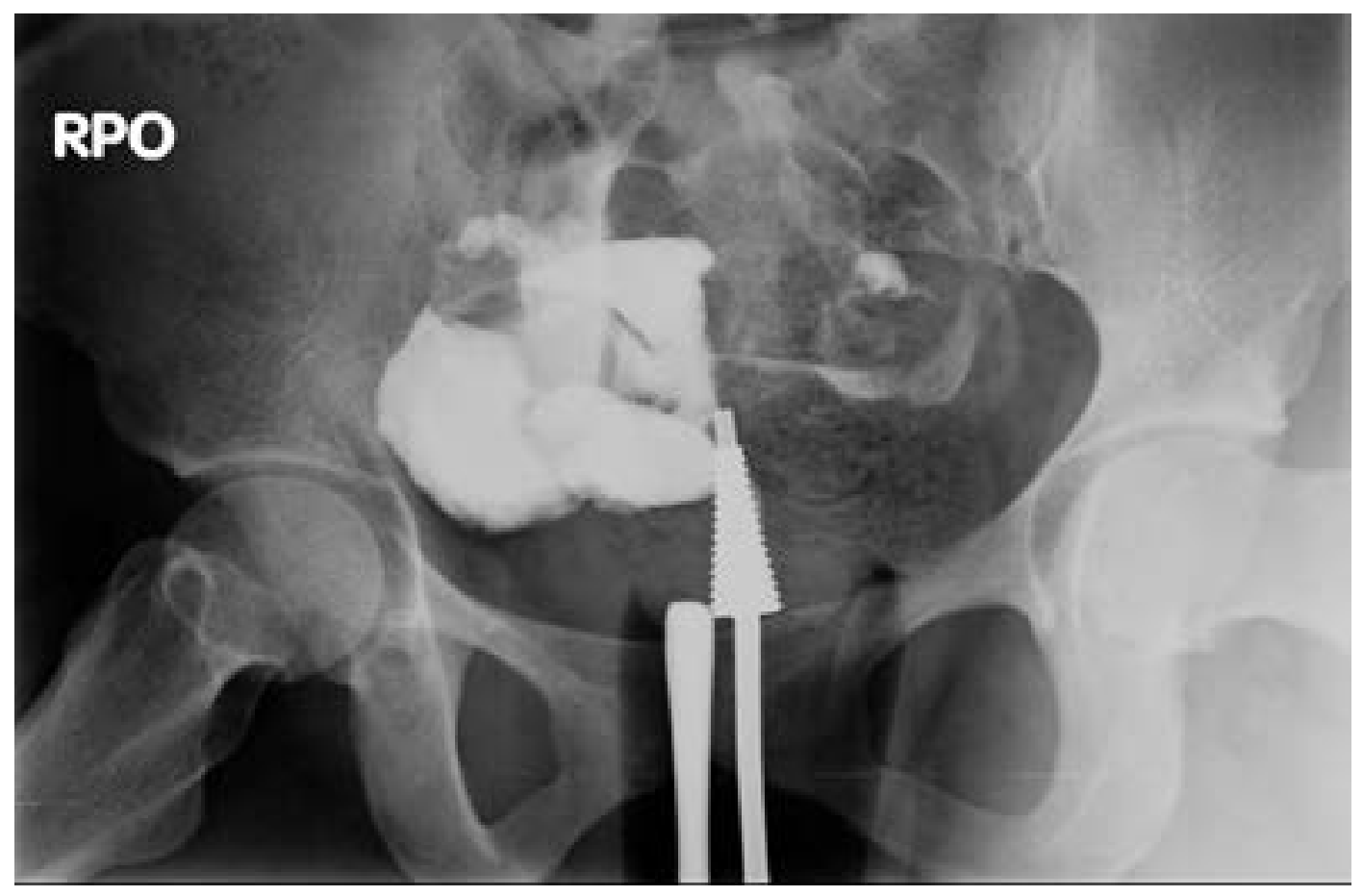

FIG 3: Hysterogram demonstrates normal uterine cavity with right hydrosalpinx

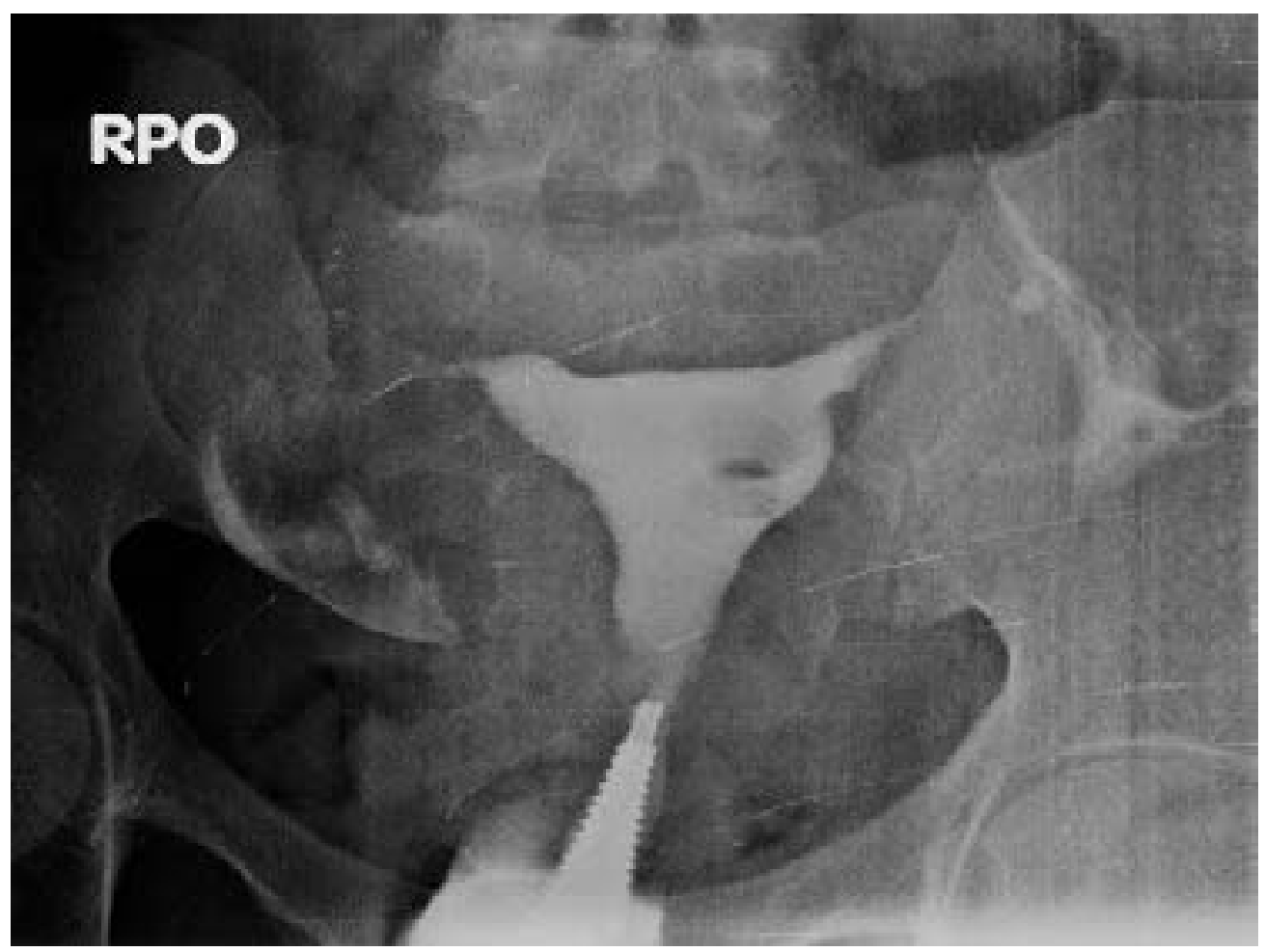

FIG 4: Hysterosalpingogram shows tubal patency with a filling defect in the uterine cavity, likely a $\mathrm{r}$ 


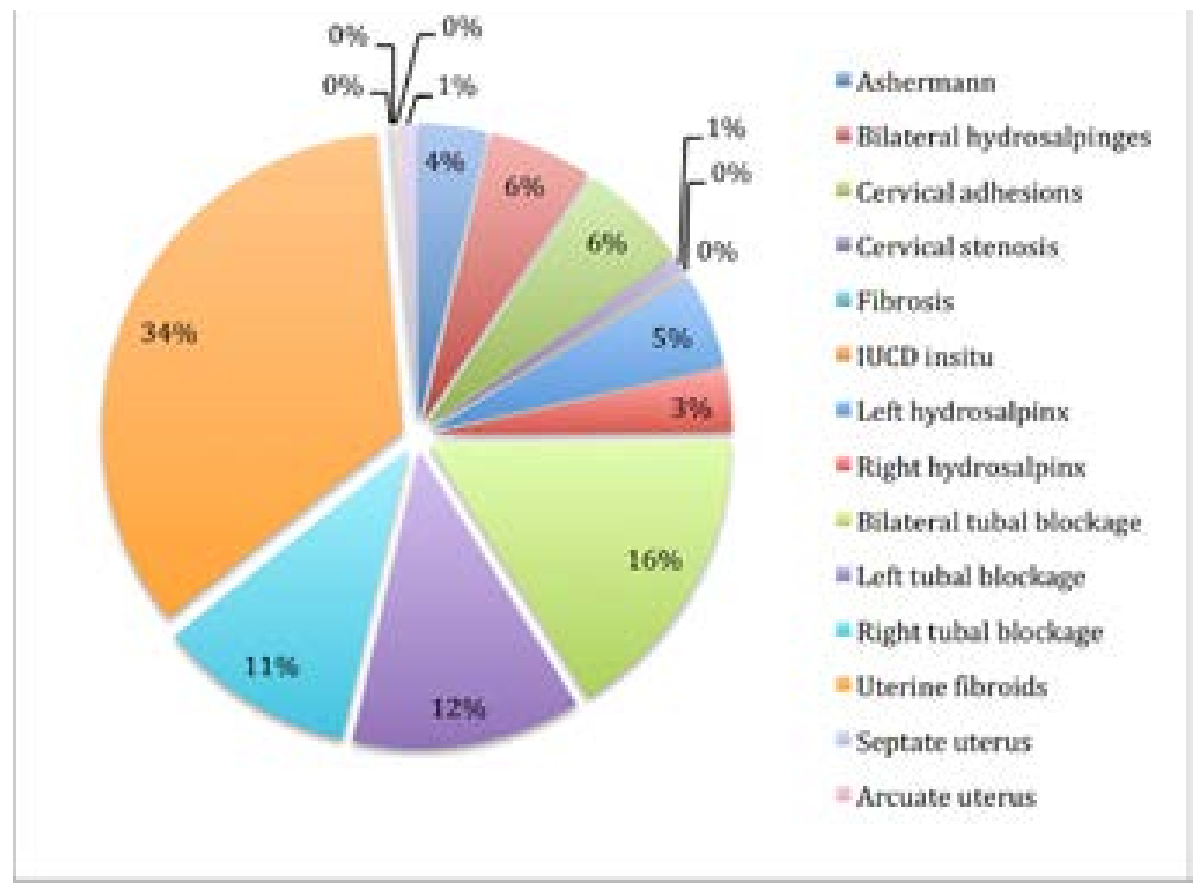

FIG 5: Distribution of abnormal findings in the study.

Regarding the number of abnormalities per hysterogram and their correlation with spillage, Table 2 shows that the more the abnormalities, the less the percentage of tubal spillage seen. This finding was statistically significant.
Table 3 shows the pattern of tubal findings across different studies over the years. There is an increase in the percentage of normal tubes seen. Similarly an increase in proportion of patients with uterine leiomyomas is also noted.

Table 2: Frequency of findings per hysterosalpingogram with presence of spillage in the study

\begin{tabular}{llll}
\hline $\begin{array}{l}\text { Number of anomalies (percent) } \\
\text { N 974 (100) }\end{array}$ & Spillage Present & Spillage absent & \\
\hline No anomaly 459 (47.1) & $457(99.6)$ & $2(0.4)$ & \\
Single 362 (37.2) & $288(79.6)$ & $74(20.4)$ & \\
Double 150 (15.4) & $79(52.7)$ & $71(47.3)$ & $\quad$ < 0.01 \\
Triple 3(0.3) & $1(33.3)$ & $2(66.7)$ & \\
\hline
\end{tabular}


Table 3: Pattern of tubal findings across studies conducted 2003 till date

\begin{tabular}{|c|c|c|c|c|c|c|c|c|c|c|c|}
\hline $5 \mathrm{~s}$ & 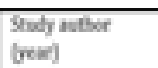 & $\begin{array}{l}\text { Meration } \\
\text { Mont ays }\end{array}$ & Narmal & $\begin{array}{l}\text { Uherins } \\
\text { myen }\end{array}$ & $\begin{array}{l}\text { Uberine } \\
\text { nhesioms }\end{array}$ & $\begin{array}{l}\text { Cenvial } \\
\text { patholog }\end{array}$ & $\begin{array}{l}\text { Sormil } \\
\text { Wules }\end{array}$ & $\begin{array}{l}\text { That } \\
\text { ocolusing }\end{array}$ & 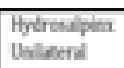 & Maldond; & Muliphicip \\
\hline 1 & 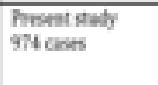 & $\begin{array}{l}21-55 y \\
330 y\end{array}$ & 675 & 225 & $167 \%$ & $7 \mathrm{n}$ & $\operatorname{sen}$ & 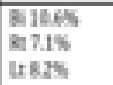 & $\begin{array}{l}\pi 236 \\
4335\end{array}$ & 365 & $15 \pi \%$ \\
\hline 2 & $\begin{array}{l}\text { Orwuthina } \\
\text { (2015) } \\
250 \text { cans }\end{array}$ & $\begin{array}{l}5+4 y \\
x-2 y\end{array}$ & 2825 & $10 \mathrm{~m}$ & $120 \%$ & $201 \%$ & क्रत & $\begin{array}{l}\text { Ret } \\
\text { unim }\end{array}$ & $\begin{array}{l}\text { Reth } \\
\text { Leth }\end{array}$ & $\mathbf{s} / \pi$ & $\mathrm{s} / \pi$ \\
\hline 3 & 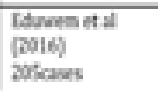 & $\begin{array}{l}21-5,5 y \\
36 y\end{array}$ & 145 & $415 \%$ & 92166 & $736 \%$ & $\Delta \mathrm{BW}$ & $20 \mathrm{~m}$ & गSE\% & $\mathrm{sy \mu}$ & $185 \mathrm{~m}$ \\
\hline 7 & $\begin{array}{l}\text { Lawan } \\
\text { 2aveavet } \\
\text { (2015) }\end{array}$ & $\begin{array}{l}18.469 \\
27.6\end{array}$ & क्रा & Satid & & & 35 & $\begin{array}{l}\text { siss } \\
\text { sis } 15 \% \\
412 \% \mathrm{~s}\end{array}$ & 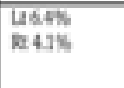 & 7 & $\mathrm{~s} / \pi$ \\
\hline 5 & 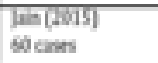 & $30-159$ & $\overline{R / A}$ & $\mathrm{X} / \mathrm{A}$ & $\mathrm{N} / \mathrm{A}$ & vis & The & $30 \%$ & $\mathrm{~N} / \mathrm{h}$ & $\mathrm{sp \mu}$ & $s / \mu$ \\
\hline 6 & 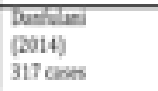 & $\begin{array}{l}77-467 \\
325 y\end{array}$ & 41DS & 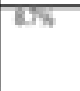 & 745 & DSW & करक & 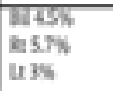 & 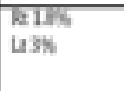 & $30 \%$ & $\mathrm{sp \pi}$ \\
\hline 7 & 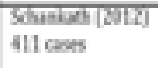 & Noi & 356 & 60 & W60 & S/T & sh & 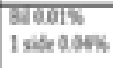 & $\mathrm{N} / \mathrm{N}$ & $\mathrm{s} / \mathrm{k}$ & बकात \\
\hline 8 & $\begin{array}{l}\text { Trar } \\
\text { (2011) } \\
\text { 27zcoses }\end{array}$ & $\begin{array}{l}1515 y \\
\text { vas }\end{array}$ & 2035 & उल & $12 \mathrm{~m}$ & का & 21क & $\begin{array}{l}\text { Mash } \\
\text { eith } \\
\text { trim }\end{array}$ & $\begin{array}{l}\text { kass } \\
\text { and }\end{array}$ & MISK & 1650 \\
\hline 9 & $\begin{array}{l}\text { Gaker (Dwed) } \\
32 \text { anks }\end{array}$ & $\begin{array}{l}19-4 \sqrt{y} \\
203 y\end{array}$ & उद्र & $2 \pi 6$ & $\mathrm{~N} / \mathrm{A}$ & $\mathrm{s} / \mathrm{I}$ & $3 \pi$ & 20 & & & \\
\hline 11 & 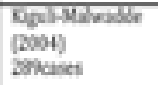 & $86-197$ & 1605 & $\begin{array}{l}\text { IDVW } \\
\text { myona }\end{array}$ & santribers & उ13m & 27.10 & 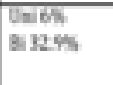 & & $12 \pi$ & $\mathrm{s} / \mathrm{\mu}$ \\
\hline 16 & 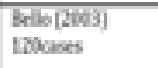 & $\begin{array}{l}19=5 y \\
2989\end{array}$ & $\mathrm{~N} / \mathrm{A}$ & $\mathrm{N} / \mathrm{A}$ & $\mathrm{N} / \mathrm{A}$ & s/a & $60 \%$ & $\begin{array}{l}\text { Geile 1135 } \\
\text { s.75s }\end{array}$ & $11 \% \%$ & tLF & $s / \pi$ \\
\hline 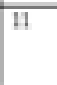 & 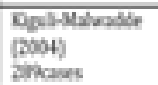 & $36-10 y$ & $16 \mathrm{~W}$ & \multicolumn{2}{|c|}{ 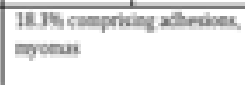 } & IISW & $27.1 \%$ & 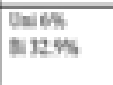 & \multicolumn{2}{|l|}{$12 \%$} & $\mathrm{~s} / \mathrm{A}$ \\
\hline II & 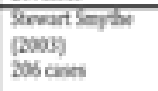 & 25,5 & 7155 & $\mathrm{X} / \mathrm{A}$ & & $\mathrm{p} / \mathrm{I}$ & 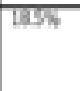 & $\begin{array}{l}\text { Uanis. } \\
\sin 65.5 \%\end{array}$ & \multicolumn{2}{|l|}{465} & $\mathrm{~s} / \mathrm{x}$ \\
\hline
\end{tabular}

\section{Discussion}

Infertility is a menace with untoward emotional, financial and sometimes traumatic consequences. It may result in abandonment and divorce particularly in sub-Saharan Africa where the fault is assumed to lie mainly on the woman. Assisted conception has helped many overcome the hurdle, however it is not readily available and affordable. HSG is one of the imaging modalities used as a first line investigation in the evaluation of infertility. ${ }^{7}$ It is used mainly to assess tubal factor infertility and to outline the uterine cavity.

The age range in this study was $20-52$ years of age. This is unlike some prior and older studies in 2003 and 2004 in which women presented as early as 18 years of age. ${ }^{1,6,11}$ The lower limit may be attributed to early marriages and lack of education noted in that period; while the upper limit may be due to assisted conception techniques that are now offered increasing the chances for perimenopausal women. Newer studies in the same population however had similar age ranges as this study. ${ }^{12,13}$ The mean age in this age group was also higher than that of the older studies but similar to those of the new studies likely because their upper limits were less than noted in the newer studies.

Normal uterine cavity is seen as an inverted triangular shape. The apex and base of the triangle are representative of the internal os and fund us respectively. Normal width of the uterine cavity is between $27-32 \mathrm{~mm}$. The cavity was of normal size in majority of the cases $(79.2 \%)$ in this study, and this agreed with a previous study. ${ }^{12}$ Uterine myomas were the second most common abnormality in this study accounting for $22.9 \%$ of the population and were preponderant in the large uteri. These 
myomas were seen as impressions or filling defects when located in the sub mucous region. This is contrary to what was found by another study ${ }^{13}$ that reported uterine fibroids as the commonest anomaly, constituting $41.95 \%$ in 205 infertile women in Calabar. The difference may be due to diet (red meat and alcohol intake increases the risk of developing myomas ${ }^{14}$ ) and other cultural differences. Adhesions are scars that occur due to endometrial destruction from trauma to the basal layer, post dilation and curettage, infections, surgeries or after complicated deliveries. ${ }^{15}$ In this study, adhesions were present in about $15 \%$ of the population, similar to other studies. ${ }^{12,16}$ Kiguli et al reported a higher percentage of filling defects, however his number comprised myomas, polyps and adhesions. ${ }^{11}$ Bukar et al also reported a similar percentage of $13 \%$ in a 7 year review of hysterosalpingographic findings in 272 infertile women in Maiduguri. ${ }^{17}$

The World Health Organization in 1976 reported that tubal occlusion and acquired tubal anomalies accounted for $85 \%$ of infertility in Africa. ${ }^{18}$ Stewart-Smythe et al in an article on lessons learned from the public sector in Uganda, also documented tubal pathology in $82.5 \%$ of 206 women studied. ${ }^{8}$ Tubal pathologies were the most common abnormality in this study, constituting $35.1 \%$ of the cases, comprising tubal blockage and hydrosalpinges. Tubal pathologies have also been reported as the most common pathology in several studies ${ }^{6,8,9,19,20}$, but with much lower percentages in more recent studies. ${ }^{7,12,21}$. This may be adduced to younger age ranges in those older studies and the current use of antibiotics preventing infectious diseases in the more recent clime.

Hydrosalpinx was seen in $9.4 \%$ of the cases. Most were bilateral followed by left sided hydrosalpinx. This finding is similar to studies by Asaleye et $\mathrm{al}^{16}$ and Lawan et al. ${ }^{21}$ Tubal occlusion, recorded in this study as lack of peritoneal spillage was also more common bilaterally, then left sided, contrary to what was obtainable in prior studies in which right occlusion was more common due to its proximity to the appendix. ${ }^{7}$ The use of antibiotics and prompt treatment of infections preponderant in the study area may have prevented this from being the case in this study. Causes of lack of spillage have ranged from spasm, to tubal occlusion from prior surgeries, masses, ectopic pregnancies and pelvic inflammatory disease. ${ }^{22}$ The most common cause of lack of spillage in this study could be adduced to cervical stenosis, as the cervix, uterine cavity and tubes could not outlined. This is contrary to another study which documented prior pelvic surgeries as their main cause of tubal obstruction. ${ }^{22}$

HSGs with no abnormal findings were seen in $47.1 \%$ and most of them had spillage present. This is comparable with the study of Danfulani in Sokoto. ${ }^{23}$ Multiplicity of abnormalities was seen in 16\% of the cases. Edunem et al also had a multiplicity of lesions in $19.5 \%$ of cases. ${ }^{14}$ Lack of spillage increased with the multiplicity of lesions as those with triple anomalies had less spillage compared with the others, which is not unusual.

\section{Conclusion}

Tubal factors remain the most common abnormality seen in the hysterosalpingograms of infertile women in this study, though with lower prevalence compared with prior older studies. Majority of the cases of infertility had normal hysterosalpingograms with bilateral tubal patency.

\section{Recommendations}

It is understood from the study that tubal pathology is still more commonly observed in $35.1 \%$ cases, so advisable to screen and treat for PID (pelvic inflammatory disease) before HSG.

Further advocacy on safe sex and prevention of harmful practices should be an ongoing exercise.

\section{Conflict of interest}

None declared.

\section{References}

1. Bello T.O. Pattern of tubal pathology in infertile women on Hysterosalpingography in Ilorin, Nigeria. Annals of African Medicine. 2004; 3(2): 77-79

2. Ahmadi F, Haghighi H, Akhbari F. Hysterosalpingography. Middle East Fertility Society Journal 2012;17(3) : 210 - 214. https://doi.org/10.1016/j.mefs.2012.07.001

3. Bendick A. J. Present Status of Hysterosalpingography. Journal of the Mount Sinai Hospital, New York. 1947;14 (3): $739-742$.

4. Panti AA, Sununu YT. The profile of infertility in a teaching Hospital in North West Nigeria. Sahel Med J. 2014;17(1): 7-11

5. Madhok R, Taneja V. Role of sonosalpingogram in correlation to hysterosalpingogram in assessment of infertility. Int J Reprod Contracept Obstet Gynecol. 2016;5(6):19361943. DOI: http://dx.doi.org/10.18203/2320-1770. ij $\operatorname{rcog} 20161694$

6. Schankath AC, Fasching N, Urech-Ruh C, Hohl MK, 
Kubik-Huch RA. Hysterosalpingography in the workup of female infertility: indications, technique and diagnostic findings. Insights Imaging 2012; 3:475-483. DOI 10.1007/ s13244-012-0183-y

7. Adegbola O, Akindele M.O. The pattern and challenges of infertility management in Lagos, Nigeria. African Health Sciences 2013; 13(4): 1126 - 1129 http://dx.doi. org/10.4314/ahs.v13i4.37

8. Stewart-Smythe GW, van Iddekinge B. Lessons learned from infertility investigations in the public sector. South Afr Med J. 2003; 93 (2): 141-143

9. Jain P, Bansal D, Deodhar P. Re- emerging role of HSG Vs laparoscopy for infertility work- up at rural hospital set up. J Res Med Den Sci. 2015;3(4):287-9

10. Chalazonitis A, Tzovara I, Laspas F, Porfyridis P, Ptohis N, Tsimitselis G. Hysterosalpingography: Technique and applications. Current Problems in Diagnostic Radiology. 2009; 38(5):199 - 205.

doi.org/10.1067/j.cpradiol.2008.02.003

11. Kiguli-Malwadde E, Byanyima RK. Structural findings at hysterosalpingography in patients with infertility at two private clinics in Kampala, Uganda. African Health Sciences. 2004; 4(3): 178-181

12. Onwucheka CR, Oriji VK. Hysterographic (HSG) pattern of infertility in women of reproductive age. $J$ Hum Reprod Sci. 2017 Jul-Sep; 10(3): 178-184.

doi: 10.4103/jhrs.JHRS_121_16

13. Eduwem DU, AkintomideAO, Bassey DE, EkottMI. Hysterosalpingographic patterns and relevance in the management of infertility in a Nigerian tertiary health Institution. Asian Journal of Medical Sciences. 2016; 7(5): 70-74 14. Donnez J, Dolmans M. Uterine fibroid management: from the present to the future, Human Reproduction Update, 2016; 22(6), 20: 665- 686. https://doi.org/10.1093/ humupd/dmw023
15. Ahmadi F, Siahbazi Sh, Akhbari F, Eslami B, Vosugh A. Hysterographic finding in intrauterine adhesion (ashermann's syndrome): a pictorial essay. Int. J Fertil Steril. 2013; 7(3):155 - 160

16. Asaleye CM, Adetiloye VA, Oyinlola TO. Review of HSG reports done for infertility over a 10 year period. NigJ Health Sci 2004; 4: 36 - 39

17. Bukar M, Mustapha Z, Takai UI, Tahir A.Hysterosalpingographic findings in infertile women: A seven year review. Nigerian Journal of Clinical Practice. 2011;14 (2): 7074

18. BelseyM.A.Theepidemiologyofinfertility.Areviewwith particular reference to sub-Saharan Africa. Bulletin WHO 1976; (54):321

19. Ngowa JD, Kasia JM, Georges NG, Nkongo V, Sone C, Fongang E. Comparison of hysterosalpingograms with laparoscopy in the diagnostic of tubal factor of female infertility at the Yaoundé General Hospital, Cameroon. Pan Afr Med J. 2015; 22:264 - 270 doi:10.11604/ pamj.2015.22.264.8028

20. Simpson WL, Jr,Beitia LG, Mester J. Hysterosalpingography: A Reemerging Study. Radio Graphics. 2006; $26: 419-431$

21. Lawan RO, Ibinaiye PO, Onwuafua P, Hamidu A. Evaluation of Pattern of Tubo-peritoneal Abnormalities Potentially Responsible for Infertility in Zaria, Nigeria: Hysterosalpingographic Assessment. Sub-saharan Afr J Med. 2015; 2: 110 - 116. Doi 10.4103/2384-5147.164418 22. Al Subhi T, Al Jashnmi RN, Al Khaduri M, Gowri V. Prevalence of Tubal Obstruction in the Hysterosalpingogram of Women with Primary and Secondary Infertility. J Reprod Infertil. 2013;14(4):214-216. PMCID: PMC3911818 23. Danfulani M, Mohammed MS, Ahmed SS, Haruna YG. Hysterosalphingographic findings in women with infertility in Sokoto North Western Nigeria. Afr J Med Health Sci. 2014;13:19-23 